\title{
Propriedades químicas de argissolos vermelho-amarelo com e sem manejo
}

\section{agroecológico}

\author{
Chemical properties of red-yellow algorithms with and without agroecological management \\ Propiedades químicas de los argisoles rojo-amarillos con y sin manejo agroecológico
}

\begin{abstract}
Resumo
O uso intenso e/ou inadequado dos solos acarreta perda dos atributos químicos necessários para manutenção da produção agropecuária. A fertilidade do solo é apenas um entre vários fatores que determinam a magnitude do rendimento das culturas, e interfere grandemente na produtividade agrícola. Nesse contexto, objetivou-se avaliar o os efeitos nas propriedades químicas do solo frente a dois tipos de manejo com e sem métodos agroecológicos. O solo 1 recebeu manejo agroecológico (irrigação, adubação orgânica, capina, cobertura morta) e o solo 2 foi recebeu apenas gradagem e capina manual. Foram analisados o $\mathrm{pH}$, as quantidades de $\mathrm{P}, \mathrm{K}^{+}, \mathrm{Ca}^{+2}, \mathrm{Mg}^{+2}, \mathrm{Na}^{+}, \mathrm{Al}^{+3}, \mathrm{H}^{+}+\mathrm{Al}^{+3}, \mathrm{COT}$, MO, CTC, SB, V (\%) e m (\%) no período de agosto à setembro de 2016. O delineamento experimental utilizado foi o DBC com o fatorial 4 x 2 com 10 repetições. 4 níveis de profundidade $(0-5,5-10,10-15$ e $15-20 \mathrm{~cm})$ x 2 tipos de solo. O manejo empregado no solo 1 condiciona valores de $\mathrm{pH}, \mathrm{CTC}, \mathrm{SB}, \mathrm{V}(\%), \mathrm{K}^{2+}, \mathrm{Ca}^{2+}$, superiores ao solo 2 , juntamente com $\mathrm{Na}^{+}$. 2. Ambos os solos apresentaram teores similares de $\mathrm{Mg}^{2+}$ embora a SB e V (\%) seja maiores para o solo 1. 3. Os valores de $\mathrm{Al}^{3+}, \mathrm{H}^{+}+\mathrm{Al}^{3+}, \mathrm{m}(\%)$ foram maiores no solo 2, do mesmo a $\mathrm{MO}$ e o COT se encontra em nível superior. Palavras-chave: Fertilidade do solo; Agroecologia; Agricultura familiar.
\end{abstract}

\begin{abstract}
Intense and/or inadequate use of soils leads to loss of chemical attributes needed to maintain agricultural production. Soil fertility is just one of several factors that determine the magnitude of crop yields, and it greatly interferes with agricultural productivity. In this context, the objective was to evaluate the effects on the chemical properties of the soil under two types of management with and without agroecological methods. Soil 1 received agroecological management (irrigation, organic fertilization, weeding, mulch) and soil 2 received only harrowing and manual weeding. The $\mathrm{pH}$, the
\end{abstract}


amounts of $\mathrm{P}, \mathrm{K}+, \mathrm{Ca}+2, \mathrm{Mg}+2, \mathrm{Na}+, \mathrm{Al}+3, \mathrm{H}++\mathrm{Al}+3, \mathrm{COT}, \mathrm{MO}, \mathrm{CTC}, \mathrm{SB}, \mathrm{V}(\%)$ in (\%) in the period from August to September 2016. The experimental design used was the DBC with a 4 x 2 factorial with 10 repetitions. 4 depth levels $(0-5,5-10,10-15$ and $15-20 \mathrm{~cm}) \times 2$ types of soil. The management employed in soil 1 conditions values of $\mathrm{pH}$, $\mathrm{CTC}, \mathrm{SB}, \mathrm{V}(\%), \mathrm{K} 2+, \mathrm{Ca} 2+$, superior to soil 2, together with $\mathrm{Na}+$. 2. Both soils had similar Mg2+ contents although the SB and V (\%) were higher for soil 1. 3. The values of $\mathrm{Al} 3+, \mathrm{H}++\mathrm{Al}+, \mathrm{m}(\%)$ were higher in soil 2, of the same a $\mathrm{MO}$ and COT are at a higher level.

Keywords: Soil fertility; Agroecology; Family farming.

\begin{abstract}
Resumen
El uso intenso y / o inadecuado de los suelos conduce a la pérdida de los atributos químicos necesarios para mantener la producción agrícola. La fertilidad del suelo es solo uno de varios factores que determinan la magnitud de los rendimientos de los cultivos e interfiere en gran medida con la productividad agrícola. En este contexto, el objetivo fue evaluar los efectos sobre las propiedades químicas del suelo bajo dos tipos de manejo con y sin métodos agroecológicos. El suelo 1 recibió manejo agroecológico (riego, fertilización orgánica, deshierbe, mantillo) y el suelo 2 recibió solo desbroce y deshierbe manual. $\mathrm{El} \mathrm{pH}$, las cantidades de $\mathrm{P}, \mathrm{K}+, \mathrm{Ca}+2, \mathrm{Mg}+2, \mathrm{Na}+, \mathrm{Al}+3, \mathrm{H}++\mathrm{Al}+3$, COT, MO, CTC, SB, V (\%) en (\%) en el período de agosto a septiembre de 2016. El diseño experimental utilizado fue el DBC con un factorial de 4 x 2 con 10 repeticiones. 4 niveles de profundidad $(0-5,5-10,10-15$ y $15-20 \mathrm{~cm})$ x 2 tipos de suelo. El manejo empleado en el suelo 1 condiciona valores de $\mathrm{pH}, \mathrm{CTC}, \mathrm{SB}, \mathrm{V}(\%), \mathrm{K} 2+\mathrm{Ca} 2+$, superiores al suelo 2, junto con $\mathrm{Na}+$. 2. Ambos suelos tuvieron contenidos similares de $\mathrm{Mg} 2+$ aunque $\mathrm{SB}$ y $\mathrm{V}$ (\%) fueron mayores para el suelo 1. 3. Los valores de $\mathrm{Al} 3+, \mathrm{H}++\mathrm{Al} 3+\mathrm{m}(\%)$ fueron mayores en el suelo 2, de la misma a MO y COT están en un nivel superior.
\end{abstract}

Palabras clave: Fertilidad del suelo; Agroecología; Agricultura familiar.

\title{
1. Introdução
}

O solo como conhecemos atualmente é produto da ação de processos exógenos de intemperismo e pedogênese por períodos de tempo geológico. Os processos de intemperismo respondem pela quebra mecânica dos blocos de rochas e pela degradação química dos componentes minerais das rochas, e como resultado acarreta num material consolidado e alterado, que compõem o material de origem dos solos conforme Lima (2008). Essa degradação avança ao ponto de serem formados corpos naturais independentes, de constituição mineral e orgânicos dispostos em camadas em razão dos fatores de formação (material de origem, relevo, clima e organismos e tempo) (Santos et al., 2005).

O uso intenso dos solos sobre diversos tipos de manejo acarreta perda da fertilidade necessária para manutenção da produção agrícola afetando sua capacidade de recuperação (Niero et al., 2010). A fertilidade do solo é apenas um entre vários fatores que determinam a magnitude do rendimento das culturas, interferindo na produtividade agrícola (Ronquin, 2010).

Adições frequentes de matéria orgânica no cultivo do solo é a forma mais adequada e ecológica de manter e/ou aumentar a fertilidade de um solo tropical, e é responsável também por melhorar as condições físicas e químicas, a exemplo a capacidade de troca de cátions (Ribeiro at al., 2019; Santos et al., 2021). Ao passo que o uso de fertilizantes amoniacais e práticas que degradam e expõem o solo contribuem drasticamente para a perda da maior parte da mesofaúna no solo (Primavesi, 2002), considerados indicadores de qualidade do solo (Silva et al., 2019). Assim, a avaliação da comunidade do solo, como bioindicadores, tem se mostrado eficiente nas comparações de diferentes condições ambientais (Santos et al., 2017).

A agroecologia apresenta-se como modelo para agricultura para o futuro, que deve ser sustentável e altamente produtiva para atender as necessidades alimentares, bem como poder ser exercida sem prejuízos ao meio onde é praticada, pois possui aplicação de conceitos e princípios ecológicos na arquitetura e manejo de agroecossistemas sustentáveis (Altieri, 2012). Estes princípios são essenciais para determinar se uma prática, insumo ou decisão é sustentável e a base ecológica para funcionamento a longo prazo do caminho traçado. E é o conhecimento ecológico de manutenção dos agroecossistemas que dará nova perspectiva à humanidade para a produção sustentável de alimentos no âmbito animal e vegetal (Gliessman, 2000; Primavesi, 2002). 
As práticas de manejo agroecológico do solo visam não apenas o equilíbrio dos processos produtivos, mas sobretudo a manutenção da fertilidade do solo de forma sustentável e economicamente viável. Nesse contexto o nível de alteração na qualidade sofridas pelo solo pode ser avaliado pela quantificação do estado atual de determinados atributos e comparados com valores considerados ideais (Silva et al., 2015).

O presente trabalho teve como objetivo avaliar o os efeitos nas propriedades químicas do solo frente a dois tipos de manejo com e sem métodos agroecológicos.

\section{Metodologia}

As amostras de solos do ambiente de estudo foram recolhidas no P. A. (Projeto de Assentamento) Rainha dos Anjos, localizado na cidade de Sapé, PB, (CPRM, 2005), localizado na Microrregião de Sapé e na Mesorregião Mata Paraibana, no Estado da Paraíba. O clima é do tipo As' de acordo com Köppen (Paraíba, 2008), com caracteres de quente e úmido e pluviosidade que ocorrem de outono e inverno. Expressa períodos de estiagem médios de cinco a seis meses. As temperaturas variam de $22^{\circ} \mathrm{C}$ a $26^{\circ} \mathrm{C}$. O clima de Sapé é do tipo Tropical Chuvoso com verão seco. O período chuvoso começa no outono tendo início em fevereiro e término em outubro. A precipitação média anual é de 1.634,2 mm (Tabela 1). Os solos dessa unidade geoambiental são representados pelos Argissolos Vermelho-Amarelos (Embrapa, 2006).

Tabela 1 - Índice pluviométrico no município de Sapé-PB, nos últimos anos.

\begin{tabular}{ll}
\hline Ano & Pluviosidade \\
\hline 2012 & $1.031,9 \mathrm{~mm}$ \\
2013 & $1.242,1 \mathrm{~mm}$ \\
2014 & $1.081,3 \mathrm{~mm}$ \\
2015 & $1.047,0 \mathrm{~mm}$ \\
2016 & $1.064,3 \mathrm{~mm}$ \\
Média dos últimos 30 anos (1990) & $1.029 .3 \mathrm{~mm}$ \\
\hline
\end{tabular}

Fonte: http://www.aesa.pb.gov.br/

A coleta das amostras de solo foram realizadas em duas áreas distintas, a primeira área localizada a $07^{\circ} 6^{\prime} 58.86^{\prime \prime} \mathrm{S} 35^{\circ}$ 10' 43.13" W, sob tratamento de solo com manejo agroecológico, (uso de adubos orgânicos, cobertura morta, defensivos naturais, rotação de cultura) e rotação de culturas e a segunda área localizada em $07^{\circ} 6^{\prime} 58.26^{\prime \prime} \mathrm{S} 35^{\circ} 10^{\prime} 44.80^{\prime \prime} \mathrm{W}$ sem quaisquer tratamentos recebendo apenas gradagem e colocada para cultivo solteiro em sequeiro e pousio uma vez que só era possível obter uma produção por ano. As amostras foram coletadas em duas áreas medindo 1,0 ha, a escolha dos pontos se deu de forma aleatória em zigue-zague. $\mathrm{O}$ delineamento experimental utilizado foi o delineamento em blocos ao acaso com o fatorial 4 x 2 com 10 repetições. 4 níveis de profundidade $(0-5,5-10,10-15$ e 15-20 cm) x 2 tipos de solo (Solo 1 com manejo agroecológico e solo 2 com manejo convencional) em 10 pontos de coleta, em um total de 80 amostras. As coletas foram realizadas com uso de enxada e enxadão, trena, faca. As amostras foram colocadas em sacos e identificadas por sua profundidade, número e data, e tipo de solo.

As análises foram realizadas no Laboratório de Solos do Centro de Ciências Humanas, Sociais e Agrárias (CCHSA) da Universidade Federal da Paraíba (UFPB), Campus III, no município Bananeiras-PB. Foram analisados o pH, as quantidades de $\mathrm{P}, \mathrm{K}^{+}, \mathrm{Ca}^{+2}, \mathrm{Mg}^{+2}, \mathrm{Na}^{+}$, carbono orgânico total, acidez ativa, acidez trocável, matéria orgânica, capacidade de troca de cátions, 
soma de bases, saturação por bases e saturação por alumínio de acordo com Embrapa (1997), no período de julho a agosto de 2016. Os dados foram avaliados utilizando o procedimento ANOVA com o software Assistat. 7.7 pt. O nível de probabilidade considerado foi $5 \%$ pelo teste de Tukey.

\section{Resultados e Discussão}

Os solos foram avaliados de acordo com a camada arável, Tabela 2 no qual não houve diferença significativa entre as profundidades de $\mathrm{pH}$ para ambos os dos solos pelo teste de Tukey a 5\%, esse fato se justifica pela tênue distinção que há entre essas camadas analisadas, uma vez que se trata de mesmo solo, entretanto houve diferença entre os dois solos avaliados, no qual o solo 2 possui maior acidez. A disponibilidade de nutrientes no solo depende da faixa de $\mathrm{pH}$ em que este se encontra, nesse caso a faixa de pH entre 6,0 e 6,5 é dita como ideal para a maioria das plantas cultivadas no Brasil (Lopes, 1998).

Tabela 2 - Acidez Ativa de acordo com a profundidade de coleta de amostra em dois tipos de solo.

\begin{tabular}{cccc}
\hline \multirow{2}{*}{ Profundidade $(\mathrm{cm})$} & \multicolumn{2}{c}{ Tipos de solo } & Média \\
\cline { 2 - 3 } & Solo 1 & Solo 2 & $5,38 \mathrm{a}$ \\
$0-5$ & 5,47 & 5,29 & $5,31 \mathrm{a}$ \\
$5-10$ & 5,35 & 5,26 & $5,28 \mathrm{a}$ \\
$10-15$ & 5,34 & 5,23 & $5,28 \mathrm{a}$ \\
$15-20$ & 5,39 & 5,17 & - \\
Média & $5,39 \mathrm{~A}$ & $5,23 \mathrm{~B}$ & \\
\hline
\end{tabular}

Médias seguidas pela mesma letra, minúscula nas colunas e maiúsculas nas linhas, não diferem entre si pelo teste de Tukey a $5 \%$ de probabilidade. Fonte: Autores (2021).

$\mathrm{O}$ pH do solo 1 está mais elevado que o solo 2, tal situação sob esse aspecto pode ser justificado pois, o pH pode ter sofrido alterações também em detrimento do tipo de cultivo empregado no solo, culturas diferentes removem ácidos quando as colheitas removem as bases (Lopes, 1998). Valores mais elevados de pH podem estar relacionados a decomposição da matéria orgânica (Alleoni; Melo, 2009).

Na tabela 3 os teores de CTC estão mais elevados no solo 2, e pode ser explicado pela presença de matéria orgânica em quantidades mais altas aumentando os valores de CTC total. Porém quando há níveis mais elevados de matéria orgânica no solo como mostra a Tabela 3, e mais ácido como na tabela 1, poderá apresentar baixos valores de CTC efetiva (Ronquim, 2010).

Tabela 3 - Níveis de CTC de acordo com a profundidade de coleta de amostra em dois tipos de solo.

\begin{tabular}{|c|c|c|c|}
\hline \multirow{2}{*}{ Profundidade (cm) } & \multicolumn{2}{|c|}{ Tipos de solo } & \multirow{2}{*}{ Média } \\
\hline & Solo 1 & Solo 2 & \\
\hline \multicolumn{4}{|c|}{-------- CTC $\left(\mathrm{cmol}_{\mathrm{c}} / \mathrm{dm}^{3}\right)$-------- } \\
\hline $0-5$ & 18,00 & 18,87 & $18,44 \mathrm{a}$ \\
\hline $5-10$ & 17,81 & 18,76 & $18,28 \mathrm{a}$ \\
\hline $10-15$ & 18,41 & 18,97 & $18,69 \mathrm{a}$ \\
\hline $15-20$ & 18,46 & 19,13 & $18,80 \mathrm{a}$ \\
\hline Média & $18,17 \mathrm{~A}$ & $18,93 \mathrm{~B}$ & - \\
\hline
\end{tabular}

Médias seguidas pela mesma letra, minúscula nas colunas e maiúsculas nas linhas, não diferem entre si pelo teste de Tukey a 5\% de probabilidade. Fonte: Autores (2021). 
Primavesi (2006) identificou elevação da CTC em detrimento da influência da matéria orgânica, que não é essencialmente um adubo em forma orgânica, mas um condicionador biofísico do solo que age recuperando sua porosidade. Além disso, por possuir baixa densidade em relação aos minerais, influi sobre a densidade aparente do solo. A manutenção de um nível adequado de matéria orgânica no solo contribui para melhorara o poder tampão do solo e diminuir os perig os de desequilíbrios minerais causados por uma adubação desmedida (Ronquim, 2010).

Leite (2016) afirma que o cultivo de plantas de cobertura em sistema de plantio direto pode favorecer o acúmulo de MO nos solos e aumentar a eficiência da ciclagem dos nutrientes nestes. O emprego de métodos de preparo de solo varia desde aqueles que causam intensa mobilização do solo, como o preparo convencional, até aos chamados preparos conservacionistas (Deperon Júnior, 2016).

Tabela 4. Níveis de Matéria Orgânica de acordo com a profundidade de coleta de amostra em dois tipos de solo.

\begin{tabular}{|c|c|c|c|}
\hline \multirow{2}{*}{ Profundidade $\mathrm{cm}$} & \multicolumn{2}{|c|}{ Tipos de solo } & \multirow{2}{*}{ Média } \\
\hline & Solo 1 & Solo 2 & \\
\hline \multicolumn{4}{|c|}{------- M O (g/kg) ----- } \\
\hline $0-5$ & 34,70 & 37,80 & $36,25 \mathrm{a}$ \\
\hline $5-10$ & 33,95 & 37,33 & $35,64 \mathrm{a}$ \\
\hline $10-15$ & 32,95 & 36,31 & $34,63 \mathrm{a}$ \\
\hline $15-20$ & 33,92 & 36,20 & $35,06 \mathrm{a}$ \\
\hline Média & $33,88 \mathrm{~A}$ & $36,91 \mathrm{~B}$ & - \\
\hline
\end{tabular}

Médias seguidas pela mesma letra, minúscula nas colunas e maiúsculas nas linhas, não diferem entre si pelo teste de Tukey a 5\% de probabilidade. Fonte: Autores (2021).

$\mathrm{Na}$ Tabela 4, verifica-se os que independentemente da profundidade não há diferença significativa para a MO a 5\% pelo teste de Tukey, embora haja elevação mínima, dessa forma que são iguais estatisticamente. Esse fato demostra que a matéria orgânica, se encontram presentes em toda camada arável, e não há área de concentração em nenhuma das profundidades avaliadas.

Observa-se uma maior concentração de matéria orgânica no solo 2, que pode ser definido como restos do material anterior existente no solo, uma vez que este era submetido a pousio. Embora haja um teor mais elevado esse fato não está associado a melhor qualidade desta, uma vez que houve utilização de compostagem no solo 1, e Cotta et al. (2015), perceberam que essa técnica permite o enriquecimento da $\mathrm{MO}$, no qual eleva a disponibilização de nutrientes de maneira mais econômica e sustentável ambientalmente.

A conversão dos ecossistemas naturais em ambientes de cultivo altera a dinâmica de carbono no solo, essas modificações acarretam em redução no teor de carbono orgânico-CO do solo continuamente, devido a redução do aporte, perdas por erosão e por decomposição da matéria orgânica (Hickmann; Costa, 2012). O sistema de manejo do solo está inteiramente ligado ao estoque de carbono nos solos e práticas que busquem a deposição de restos culturais atingem maior acúmulo de carbono no solo devido a cobertura morta restante (Hickmann; Costa, 2012; Sales et al., 2016; Campos et al., 2016).

Não houve diferença média significativa entre as profundidades avaliadas quanto ao teor de Carbono Orgânico-CO pelo teste de Tukey a 5\% de probabilidade. Entretanto houve Significância entre os tipos de solos avaliados, no qual o solo 2 possui maior quantidade de $\mathrm{CO}$, justificado acompanhando o teor mais elevado de matéria orgânica contido neste. Esse fato pode ter ocorrido por restos vegetais ainda não decompostos do ano anterior, uma vez que o solo é cultivado em sequeiro e após a colheita retorna para pousio. 
Tabela 5 - Níveis de Carbono Orgânico Total de acordo com a profundidade de coleta de amostra em dois tipos de solo

\begin{tabular}{|c|c|c|c|}
\hline \multirow{2}{*}{ Profundidade $(\mathrm{cm})$} & \multicolumn{2}{|c|}{ Tipos de solo } & \multirow{2}{*}{ Média } \\
\hline & Solo 1 & Solo 2 & \\
\hline \multicolumn{4}{|c|}{------ COT (g/kg) ------ } \\
\hline $0-5$ & 20,12 & 21,92 & $21,02 \mathrm{a}$ \\
\hline $5-10$ & 19,69 & 21,65 & $20,67 \mathrm{a}$ \\
\hline $10-15$ & 19,11 & 21,06 & $20,08 \mathrm{a}$ \\
\hline $15-20$ & 19,67 & 20,99 & $20,33 \mathrm{a}$ \\
\hline Média & $19,65 \mathrm{~A}$ & $21,41 \mathrm{~B}$ & \\
\hline
\end{tabular}

Médias seguidas pela mesma letra, minúscula nas colunas e maiúsculas nas linhas, não diferem entre si pelo teste de Tukey a $5 \%$ de probabilidade. Fonte: Autores (2021).

Souza et al. (2016) encontraram em análise de Gleissolos melhorias das propriedades químicas do solo, com destaque aos níveis de fósforo e cálcio relacionados a maiores quantidades de carbono orgânico contido nestes solos. Magalhaes et al. (2016) afirmam que o uso de resíduos orgânicos adequadamente tratados nos solos agrícolas, permite aumentar o conteúdo de carbono e nutrientes, a capacidade de troca catiônica e o pH.

O fósforo é um dos macronutrientes primordiais, entretanto é um dos menos absorvidos pelas plantas. Sendo este, o elemento mais empregado no Brasil em adubação de manutenção e correção de grandes culturas segundo Vilar e Vilar, (2013). Esta controvérsia se dá pela intensa interação que o fósforo apresenta com os solos que são altamente intemperizados (Vilar et al., 2010). Sob condições de pouca disponibilidade no solo deste nutriente, as plantas tendem a absorver quantidade menores, no entanto sua a utilização tende a ser mais eficaz como afirma Vilar e Vilar, (2013).

A absorção de fósforo pode ser estimulada pela aplicação de outros nutrientes, tais como o cálcio utilizado solos ácidos e o enxofre em solos básicos tem influência aparente no aumento da disponibilidade deste nutriente para as plantas, do mesmo modo, efeito do positivo também apresenta o nitrogênio na absorção de fósforo (LOPES, 1998).

Leite et al. (2016), identificaram que o cultivo de crotalária (Crotalaria juncea), lablab (Dolichos lablab) e mucuna (Mucuna aterrima) como plantas de cobertura em pré-safra de milho aumenta o $\mathrm{P}$ orgânico moderadamente lábil na camada superficial do solo, se comparado ao pousio (vegetação espontânea).

Na tabela 6 observou-se que houve diferença significativa entre as médias no fator profundidade, de modo que há uma concentração superior de fósforo na camada de $0-5 \mathrm{~cm}$ tanto no solo 1 quanto no solo 2 . Entretanto pelo teste de Tukey a $5 \%$ de probabilidade as camadas de 5-10, 10-15 e 15-20 cm não diferem entre si, esse fato pode ter sido gerado em detrimento do maior teor de matéria orgânica nesta camada, uma vez que sua maior concentração pode gerar disponibilização deste nutriente primário e sua ausência causa adsorção e indisponibilidade as plantas (Donagemma et al., 2008). O manejo do solo pode modificar a dinâmica do fósforo, alterando o conteúdo das diferentes formas de P no solo (Partelli, 2009). 
Tabela 6 - Níveis de fósforo de acordo com a profundidade de coleta de amostra em dois tipos de solo.

\begin{tabular}{cccc}
\hline \multirow{2}{*}{ Profundidade $(\mathrm{cm})$} & \multicolumn{2}{c}{ Tipos de solo } & Média \\
\cline { 2 - 3 } & Solo 1 & Solo 2 & $19,00 \mathrm{a}$ \\
$0-5$ & 20,71 & 17,29 & $14,63 \mathrm{~b}$ \\
$5-10$ & 14,96 & 14,30 & $13,25 \mathrm{~b}$ \\
$10-15$ & 14,10 & 12,40 & $13,97 \mathrm{~b}$ \\
$15-20$ & 17,35 & 10,58 & - \\
\hline
\end{tabular}

Médias seguidas pela mesma letra, minúscula nas colunas e maiúsculas nas linhas, não diferem entre si pelo teste de Tukey a $5 \%$ de probabilidade. Fonte: Autores (2021).

Foi observado que há diferença entre as médias no fator solo, no qual o solo 1 possui maior quantidade de fósforo que o solo 2. Esse fato pode ser explicado pela presença de outras fontes de fósforo como húmus, esterco, os microoganismos e os corpos dos insetos ou de outras formas de vida em decomposição em maiores quantidades no solo 1 (Lopes, 1998). Silva et al. (2015) encontrou valores superiores de P em solo tratados com manejo orgânico em comparação com manejo convencional. Coerentemente, Souza et al. (2016), encontraram uma relação positivamente entre o teor de Fósforo e quantidade de carbono orgânico no solo escuro antropogênico na Amazônia oriental.

O fósforo tem grande importância para as plantas, pois atua na fotossíntese, respiração, armazenamento e transferência de energia, divisão celular e melhora a eficiência do uso de água (Lopes, 1998; Novais, et al.; 2007). Nesse contexto Kuwahara et al. (2016) constatou o efeito mitigador de deficiência hídrica do P especialmente sobre a manutenção do crescimento radicular e o número de perfilhos em Poaceae.

$\mathrm{Na}$ Tabela 6 foram apresentados os valores de potássio encontrados nos solos 1 e 2, no qual houve diferenças significativas pelo teste de Tukey a $5 \%$ de probabilidade entre as profundidades, demostrando que a maior concentração deste macronutriente estava alocado na parcela mais superficial de ambos os solos, esse fato pode ser justificado pela ciclagem de nutrientes ou mesmo adsorvido a argila e a matéria orgânica no solo. Do mesmo modo houve diferença significativa entre as médias do solo 1 e 2 . Observou-se que há um aporte maior no solo 1 em detrimento cuja fertilidade.

Tabela 7 - Níveis de Potássio de acordo com a profundidade de coleta de amostra em dois tipos de solo.

\begin{tabular}{cccc}
\hline \multirow{2}{*}{ Profundidade $(\mathrm{cm})$} & \multicolumn{2}{c}{ Tipos de solo } & \multirow{2}{*}{ Média } \\
\cline { 2 - 3 } & Solo 1 & Solo 2 & $0,234 \mathrm{a}$ \\
$0-5$ & 0,270 & 0,199 & $0,161 \mathrm{~b}$ \\
$5-10$ & 0,270 & 0,159 & $0,142 \mathrm{bc}$ \\
$10-15$ & 0,142 & 0,143 & $0,110 \mathrm{c}$ \\
$15-20$ & 0,123 & 0,097 & - \\
Média & $0,175 \mathrm{~A}$ & $0,149 \mathrm{~B}$ & $-\mathrm{K}^{+}\left(\mathrm{cmol}_{\mathrm{d}} / \mathrm{dm}^{3}\right)$ - \\
\hline
\end{tabular}

Médias seguidas pela mesma letra, minúscula nas colunas e maiúsculas nas linhas, não diferem entre si pelo teste de Tukey a 5\% de probabilidade. Fonte: Autores (2021).

Não houve correlação de $\mathrm{K}^{+}$com a CTC do solo, uma vez que no solo como mostra a Tabela 2 os maiores valores de CTC forma encontrados no solo 1. Embora Werle, (2008) afirme que a CTC é o principal fator que determina a maior ou 
menor relação K trocável/K da solução do solo. Nesse caso observado a presença de minerais e a ciclagem de nutrientes ocorrido em cada solo pode ser responsável por essa divergência.

A capacidade de suprimento de potássio bem como sua disponibilidade no solo às plantas, está sujeito a existência de minerais primários e secundários, do fornecimento por meio de fertilizantes e da CTC do solo, além da ciclagem do próprio nutriente pelas plantas (Werle et al., 2008). A associação do esterco bovino com cloreto de potássio na forma de $\mathrm{K}_{2} \mathrm{O}$ na dose de $2.520 \mathrm{~g}_{\text {buraco }}{ }^{-1}$ promoveu melhores resultados nas doses 11 e $13 \mathrm{~kg} \mathrm{ha}^{-1} \mathrm{de}_{2} \mathrm{O}$ (Nascimento, 2016).

Observou-se na Tabela 7 que ocorre similaridade entre o fator profundidade do solo, a qual não diferiu na quantidade de cálcio pelo teste de Tukey a 5\% de probabilidade. Nesse contexto não há concentração de $\mathrm{Ca}^{+}$em nenhuma das parcelas da camada arável analisadas, dessa maneira não é um fator significativo na avaliação dos solos em questão para este nutriente.

No tocante ao fator tipo de solo, houve divergência significativa entre as médias pelo teste de Tukey a 5\% para os solos 1 e 2, revelando que o solo 1 possui teores mais elevados de $\mathrm{Ca}^{+2}$ que o solo 2. Essa diferença pode ter sido ocasionada em virtude do manejo empregado no qual possibilitou a redução dos valores de $\mathrm{Al}^{+3} \mathrm{e}^{+}+\mathrm{Al}^{+3}$, fatores responsáveis pela inibição da absorção deste cátion (Faquin, 2005).

Tabela 8 - Níveis de Cálcio de acordo com a profundidade de coleta de amostra em dois tipos de solo.

\begin{tabular}{|c|c|c|c|}
\hline \multirow{2}{*}{ Profundidade $(\mathrm{cm})$} & \multicolumn{2}{|c|}{ Tipos de solo } & \multirow{2}{*}{ Média } \\
\hline & Solo 1 & Solo 2 & \\
\hline \multicolumn{4}{|c|}{----------- $\mathrm{Ca}^{+2}\left(\mathrm{cmol}_{\mathrm{c}} / \mathrm{dm}^{3}\right)$----------- } \\
\hline $0-5$ & 2,36 & 1,93 & $2,14 \mathrm{a}$ \\
\hline $5-10$ & 2,42 & 1,82 & $2,12 \mathrm{a}$ \\
\hline $10-15$ & 2,12 & 2,11 & $2,11 \mathrm{a}$ \\
\hline $15-20$ & 2,73 & 1,63 & $2,18 \mathrm{a}$ \\
\hline Média & $2,41 \mathrm{~A}$ & $1,87 \mathrm{~B}$ & - \\
\hline
\end{tabular}

Médias seguidas pela mesma letra, minúscula nas colunas e maiúsculas nas linhas, não diferem entre si pelo teste de Tukey a 5\% de probabilidade. Fonte: Autores (2021).

Matos et al. (1998) descobriram que a adição do gesso a compostagem proporcionou mais rápida decomposição do bagaço de cana-de-açúcar que o superfosfato triplo, adicionados ao preparo, esse fato justificaria os teores mais elevados de matéria orgânica no solo 2, cuja decomposição se dá de forma mais lenta que no solo 1.

$\mathrm{O} \mathrm{Ca}^{+}$é o cátion dominante nos pontos do complexo de troca de cátions dos solos corrigidos. Como outros cátions, o cálcio está também presente na solução do solo, e compõem a estrutura de vários minerais (Lopes, 1998).

Rodrighero et al. (2015) perceberam que a aplicação de calcário na superfície em sistemas de plantio direto, reduziu a acidez dos solos nas camadas de 0,00-0,05 m e, em menor grau, nas de 0,05-0,10 m, e verificou-se também que houve amenização da acidez nas camadas da superfície de maneira mais acentuada com a aplicação de doses mais elevadas de calcário calcítico e de corretivo com granulometria mais fina. Também foi observado que a calagem superficial aumentou os teores foliares de Ca, e a elevação de Mg nas folhas do milho (Zea mays) e soja (Glycine max) foi observada com a aplicação de calcário dolomítico.

Domingues et al. (2016), observaram que plantas de feijão comum cultivadas sob a adição de altas concentrações de Ca na solução nutritiva apresentam maior massa seca da parte aérea e raiz, alto rendimento de grãos e alta concentração de Ca nas folhas e grãos. A adição de quantidades elevadas de cálcio e magnésio em solos com deficiência de potássio, ou mesmo a aplicação de $\mathrm{Ca}$ em um solo deficiente em $\mathrm{Mg}$, pode resultar em desequilíbrio nutricional e o crescimento reduzido da cultura. (Lopes, 1998). Cardoso et al. (2016), identificaram que a cal aumenta o teor de cálcio e magnésio no solo, ao passo que os 
níveis de N, Ca e Mg nas folhas da grama Massai (Panicum maximum cv. Massai) são mais afetados pelo N aplicado ao solo do que a cal.

De acordo com a tabela 9, verifica-se que não houve diferença significativa entre as médias de profundidade pelo teste de Tukey a $5 \%$, para a quantidade de $\mathrm{Mg}^{+2}$, tais resultados podem ser devido ao fato de que os níveis analisados $(0-5,5-10,10$ 15 e 15-20 cm) pertencerem ao mesmo solo e não haver interação do magnésio em nas profundidades avaliadas.

Tabela 9 - Níveis de Magnésio de acordo com a profundidade de coleta de amostra em dois tipos de solo.

\begin{tabular}{|c|c|c|c|}
\hline \multirow{2}{*}{ Profundidade $(\mathrm{cm})$} & \multicolumn{2}{|c|}{ Tipos de solo } & \multirow{2}{*}{ Média } \\
\hline & Solo 1 & Solo 2 & \\
\hline \multicolumn{4}{|c|}{----------- $\mathrm{Mg}^{+2}\left(\mathrm{cmol}_{\mathrm{c}} / \mathrm{dm}^{3}\right)$--------- } \\
\hline $0-5$ & 3,80 & 2,66 & $3,23 \mathrm{a}$ \\
\hline $5-10$ & 2,84 & 2,98 & $2,91 \mathrm{a}$ \\
\hline $10-15$ & 2,91 & 3,07 & $2,99 \mathrm{a}$ \\
\hline $15-20$ & 3,27 & 2,91 & $3,09 \mathrm{a}$ \\
\hline Média & $3,20 \mathrm{~A}$ & $2,90 \mathrm{~A}$ & - \\
\hline
\end{tabular}

Médias seguidas pela mesma letra, minúscula nas colunas e maiúsculas nas linhas, não diferem entre si pelo teste de Tukey a $5 \%$ de probabilidade. Fonte: Autores (2021).

Do mesmo modo não houve diferença significativa entre as médias do fator solo pelo teste de Tukey a 5\% de probabilidade, haja quantidade mais elevada de $\mathrm{Mg}$ no solo 1 são estatisticamente iguais revelando que a prática de manejo não teve influência na quantidade de Mg presente, este é adsorvido às superfícies das argilas e da matéria orgânica (Lopes, 1998) e possui papel importante como macronutriente para o crescimento das plantas (Domingues et al, 2016).

Na tabela 10 observou-se que não houve diferença significativa entre as médias de valores de sódio, para as profundidades avaliadas (0-5, 5-10, 10-15 e 15-20 cm). Esse fato indica as camadas de $5 \mathrm{em} 5 \mathrm{~cm}$ subdividindo a camada arável não influenciaram nos teores de sodicidade do solo analisado.

Tabela 10 - Níveis de Sódio de acordo com a profundidade de coleta de amostra em dois tipos de solo.

\begin{tabular}{|c|c|c|c|}
\hline \multirow{2}{*}{ Profundidade $(\mathrm{cm})$} & \multicolumn{2}{|c|}{ Tipos de solo } & \multirow{2}{*}{ Média } \\
\hline & Solo 1 & Solo 2 & \\
\hline \multicolumn{4}{|c|}{ - } \\
\hline $0-5$ & 0,096 & 0,043 & $0,0696 \mathrm{a}$ \\
\hline $5-10$ & 0,101 & 0,043 & $0,0724 \mathrm{a}$ \\
\hline $10-15$ & 0,094 & 0,043 & $0,0688 \mathrm{a}$ \\
\hline $15-20$ & 0,095 & 0,043 & $0,0692 \mathrm{a}$ \\
\hline Média & $0,097 \mathrm{~A}$ & 0,043 B & - \\
\hline
\end{tabular}

Médias seguidas pela mesma letra, minúscula nas colunas e maiúsculas nas linhas, não diferem entre si pelo teste de Tukey a $5 \%$ de probabilidade. Fonte: Autores (2021).

Observa-se que há diferença nos teores de sódio, no qual o solo 1 apresenta níveis mais elevados. Essa condição pode ser explicada devido a presença de irrigação no solo 1, realizada por aspersão convencional, onde segundo Amorim, et al. (2010), tais problemas de salinidade decorrem do manejo inadequado da irrigação praticado nessas áreas, que não possuem sistema de drenagem ou mesmo não funcionam com eficiência. Segundo Melo et al. (2008), a aplicação dos níveis de 100, 125 e 150\% da necessidade de gesso mostrou-se eficiente na diminuição da Relação de Adsorção de Sódio do extrato de saturação 
dos solos, reduzindo os teores de sódio dos solos. Embora não haja problemas em ambos os solos o solo 2 apresenta possibilidade reduzida de problemas futuros causados pelo $\mathrm{Na}^{+}$.

Os níveis de $\mathrm{Al}^{+3}$ avaliados estão contidos na tabela 10. Observou-se que houve diferença significativa pelo teste de Tukey a 5\% entre as médias do fator profundidade, indicando que há mobilidade do alumínio mesmo entres as camadas mais superficiais do solo, e há similaridade entre as profundidades 0-5 e 5-10 cm, 5-10 e 10-15 cm, entretanto a 15-20 cm difere de todas, o que infere dizer, que em ambos os solos quanto maior a profundidade maior será o teor de $\mathrm{Al}^{+3}$, do mesmo modo se comporta o $\mathrm{H}^{+}+\mathrm{Al}^{+3}$.

Tabela 11 - Níveis de Acidez Trocável e Acidez Não-Trocável de acordo com a profundidade de coleta de amostra em dois tipos de solo.

\begin{tabular}{|c|c|c|c|c|c|c|}
\hline \multirow{2}{*}{ Profundidade $(\mathrm{cm})$} & \multicolumn{2}{|c|}{ Tipos de solo } & \multirow{2}{*}{ Média } & \multicolumn{2}{|c|}{ Tipos de solo } & \multirow[b]{2}{*}{ Média } \\
\hline & Solo 1 & Solo 2 & & Solo 1 & Solo 2 & \\
\hline & \multicolumn{2}{|c|}{$\mathrm{Al}^{3+}\left(\mathrm{cmol}_{\mathrm{c}} / \mathrm{dm}^{3}\right)$} & & \multicolumn{2}{|c|}{$\mathrm{H}^{+}+\mathrm{Al}^{3+}\left(\mathrm{cmol}_{\mathrm{c}} / \mathrm{dm}^{3}\right)$} & \\
\hline $0-5$ & 0,37 & 0,72 & $0,55 \mathrm{c}$ & 11,84 & 14,27 & $13,05 \mathrm{a}$ \\
\hline $5-10$ & 0,48 & 0,78 & $0,63 \mathrm{bc}$ & 11,73 & 13,62 & $12,68 \mathrm{a}$ \\
\hline $10-15$ & 0,50 & 0,90 & $0,70 \mathrm{~b}$ & 12,17 & 13,97 & $13,07 \mathrm{a}$ \\
\hline $15-20$ & 0,65 & 1,02 & $0,83 \mathrm{a}$ & 12,30 & 14,61 & $13,46 \mathrm{a}$ \\
\hline Média & $0,50 \mathrm{~A}$ & $0,85 \mathrm{~B}$ & - & $12,01 \mathrm{~A}$ & $14,12 \mathrm{~B}$ & - \\
\hline
\end{tabular}

Médias seguidas pela mesma letra, minúscula nas colunas e maiúsculas nas linhas, não diferem entre si pelo teste de Tukey a $5 \%$ de probabilidade. Fonte: Autores (2021).

$\mathrm{Na}$ tabela 11 os valores de $\mathrm{H}^{+}+\mathrm{Al}^{+3}$ mantem-se em níveis inferiores no solo 1 assim como $\mathrm{Al}^{+3}$, demonstrando que há associação entre os valores conforme os valores de m, (tabela 11), SB (tabela 12) e V (tabela 13), embora não se encontre em níveis altamente tóxicos, o manejo empregado no solo 1 possibilita menores possibilidades de toxidade futura.

Na tabela 12 estão dispostos os níveis de Saturação por Alumínio, onde houve diferença significa entre as camadas de solo onde 0-5 cm é igual a 5-10 cm, porém diverge das demais, enquanto 10-15 e 15-20 cm, enquanto estas são iguais estatisticamente a 5-10 cm pelo teste de Tukey a 5\% de probabilidade. Essa variação embora mínima indica que a maior saturação por alumínio se encontra nas maiores profundidades na camada arável analisada em consonância com os valores encontrado na Tabela 9.

Tabela 12 - Níveis de Saturação por Alumínio de acordo com a profundidade de coleta de amostra em dois tipos de solo

\begin{tabular}{cccc}
\hline \multirow{2}{*}{ Profundidade $(\mathrm{cm})$} & \multicolumn{2}{c}{ Tipos de solo } & \multirow{2}{*}{ Média } \\
\cline { 2 - 3 } & Solo 1 & Solo 2 & $10,00 \mathrm{~b}$ \\
$0-5$ & ---99 & 15,02 & $11,60 \mathrm{ab}$ \\
$5-10$ & 8,992 & 14,47 & $12,38 \mathrm{a}$ \\
$10-15$ & 8,79 & 15,98 & $13,22 \mathrm{a}$ \\
$15-20$ & 7,48 & 18,95 & - \\
Média & $7,49 \mathrm{~A}$ & $16,11 \mathrm{~B}$ & - \\
\hline
\end{tabular}

Médias seguidas pela mesma letra, minúscula nas colunas e maiúsculas nas linhas, não diferem entre si pelo teste de Tukey a $5 \%$ de probabilidade. Fonte: Autores (2021). 
Observa-se que o solo 1 possui terrores inferiores de Saturação de alumínio corroborando com os resultados para SB (tabela 12) e V\% (Tabela 13). Embora não haja necessidade de aplicação de gesso tendo em vista que a saturação por alumínio (m\%) é inferior a 40\%, como afirma Ronquim (2010). Segundo Osaki (1991), os valores de m entre 5-10\% são considerados baixos e, portanto, pouco prejudicial, enquanto os valores entre 10,1-20\% são medianamente prejudiciais as culturas.

Na tabela 13 estão dispostos os valores de soma de bases. Observou-se que não há diferença entre as médias do fator profundidade $(0-5,5-10,10-15$ e 15-20 cm) para nenhum dos solos avaliados. Desse modo infere-se dizer que não existe diferença não sendo fator significativo para análise nestes solos. Em consonância com Ronquim, (2010), a soma de bases permutáveis (SB) em um solo, argila ou húmus retrata a soma dos teores de cátions trocáveis, com exceção para o $\mathrm{H}^{+}$e $\mathrm{Al}^{3+}$ $\left(\mathrm{SB}=\mathrm{Ca}^{2+}+\mathrm{Mg}^{2+}+\mathrm{K}^{+}\right)$.

Tabela 13 - Níveis de Soma de Bases de acordo com a profundidade de coleta de amostra em dois tipos de solo.

\begin{tabular}{|c|c|c|c|}
\hline \multirow{2}{*}{ Profundidade $(\mathrm{cm})$} & \multicolumn{2}{|c|}{ Tipos de solo } & \multirow{2}{*}{ Média } \\
\hline & Solo 1 & Solo 2 & \\
\hline \multicolumn{4}{|c|}{------------- SB $\left(\mathrm{cmol}_{\mathrm{c}} / \mathrm{dm}^{3}\right.$ ) ------------- } \\
\hline $0-5$ & 6,16 & 4,60 & $5,38 \mathrm{a}$ \\
\hline $5-10$ & 6,07 & 5,13 & $5,60 \mathrm{a}$ \\
\hline $10-15$ & 6,23 & 5,00 & $5,61 \mathrm{a}$ \\
\hline $15-20$ & 6,15 & 4,51 & $5,33 \mathrm{a}$ \\
\hline Média & $6,15 \mathrm{~A}$ & $4,81 \mathrm{~B}$ & - \\
\hline
\end{tabular}

Médias seguidas pela mesma letra, minúscula nas colunas e maiúsculas nas linhas, não diferem entre si pelo teste de Tukey a 5\% de probabilidade. Fonte: Autores (2021).

No fator solo analisado houve diferença significativa entre os valores de SB, revelando que o solo 1 possui terrores de cátions trocáveis superior ao solo 2. Esse resultado pode ter sido encontrado em decorrência do manejo empregado no solo 1 que propiciou o incremento acentuado na SB. Silva et al., (2015) encontrou valores de SB superiores em cultivo orgânico, inclusive se comparado a mata nativa.

Na Tabela 13 observou-se que o fator profundidade não difere estatisticamente pelo teste de Tukey a 5\% de probabilidade nos níveis de saturação por bases, o que indica que não há distinção significativa entre a camada arável dos solos analisados.

Tabela 14 - Níveis de Saturação por Bases de acordo com a profundidade de coleta de amostra em dois tipos de solo.

\begin{tabular}{|c|c|c|c|}
\hline \multirow{2}{*}{ Profundidade $(\mathrm{cm})$} & \multicolumn{2}{|c|}{ Tipos de solo } & \multirow{2}{*}{ Média } \\
\hline & Solo 1 & Solo 2 & \\
\hline \multicolumn{4}{|c|}{--------------- V (\%) ------------- } \\
\hline $0-5$ & 34,61 & 24,50 & $29,55 \mathrm{a}$ \\
\hline $5-10$ & 34,14 & 27,53 & $30,83 \mathrm{a}$ \\
\hline $10-15$ & 33,66 & 26,47 & $30,07 \mathrm{a}$ \\
\hline $15-20$ & 33,34 & 23,78 & $28,56 \mathrm{a}$ \\
\hline Média & $33,94 \mathrm{~A}$ & $25,57 \mathrm{~B}$ & - \\
\hline
\end{tabular}

Médias seguidas pela mesma letra, minúscula nas colunas e maiúsculas nas linhas, não diferem entre si pelo teste de Tukey a 5\% de probabilidade. Fonte: Autores (2021). 
No tocante ao fator tipo de solo, verificou-se valores mais elevados de saturação por bases no solo 1 possui menor susceptibilidade a de perdas de bases. E, portanto, maior poder tampão que é a capacidade que o solo possui de resistência a mudanças bruscas de $\mathrm{pH}$, e exige doses acentuadas de calcário para atingir os valores desejados de saturação por bases (V\%) ou pH ideal. (Ronquim, 2010). Na utilização da cal para aumentar a saturação da base, o nitrogênio tem o efeito oposto na saturação por bases (Cardoso et al., 2016). Enquanto Alves et al. (2016) observaram que valores entre 47 e $48 \%$ de saturação por bases promovem os melhores resultados de matéria seca de brotação e rendimento de grãos e óleo de Crambe (Crambe abyssinica).

Não houve diferença significativa entre as profundidades analisadas $(0-5,5-10,10-15$ e 15-20 cm), o que infere dizer que não há influência nesse nível de profundidade sobre a Saturação por Bases e que toda a camada arável possui níveis similares de V\%, esse fato pode ter sido ocasionado devido as 4 amostras serem oriundas de mesmo ponto de coleta. Nesse contexto de acordo com EMBRAPA (2006), tanto o solo 1 quanto o solo 2 classificam-se como Hiperdistrófico pois encontram-se abaixo de $35 \%$ de saturação por bases.

\section{Conclusão}

O manejo empregado no solo 1 (manejo agroecológico) condiciona os valores de $\mathrm{pH}, \mathrm{CTC}, \mathrm{SB}, \mathrm{V}(\%), \mathrm{K}^{+2}, \mathrm{Ca}^{+2} \mathrm{e}$ $\mathrm{Na}^{+}$superiores ao solo 2 (manejo convencional). Ambos os solos apresentaram teores similares de $\mathrm{Mg}^{+2}$, embora a SB e V (\%) sejam maiores para o solo 1, dessa forma, o manejo nestes solos não exerce influência significativa para esse macronutriente. Os valores de $\mathrm{Al}^{+3}, \mathrm{H}^{+}+\mathrm{Al}^{+3} \mathrm{e} \mathrm{m}(\%)$ foram maiores no solo 2, assim como a MO e COT

\section{Referências}

Alleoni, L. R. F. e Melo, V. F. (2009). Química e mineralogia de solos. Sociedade Brasileira de Ciência do Solo.

Alves, M. S. (2016). Emissão de gases de efeito estufa e estoque de carbono no sistema solo-planta em função do sistema de produção e da aplicação superficial de corretivo da acidez. Dissertação de mestrado em Agronomia, Universidade Estadual Paulista- UNESP, Botucatu, SP, Brasil.

Amorim, J. R. A., Cruz, M. A. S., Resende, R. S., Bassoi, L. H., Silva Filho, J.G. (2010). Espacialização da porcentagem de sódio trocável do solo no Perímetro Irrigado Califórnia, em Canindé de São Francisco, Sergipe. Embrapa Tabuleiros Costeiros.

Banzatto, D. A. e Kronka, S. N. (2006). Experimentação agrícola. FUNESP.

Cardoso, S., Volpe, E., Macedo, M. C. M. (2016). Effect of nitrogen and lime on Massai grass subjected to intensive cutting. Pesquisa Agropecuária Tropical, $46(1), 19-27$.

Companhia De Pesquisa De Recusos Minerais-CPRM. Serviço Geológico do Brasil. Projeto cadastro de fontes de abastecimento por água subterrânea. Diagnóstico do município de Sapé, Estado da Paraíba/ (orgs.). Mascarenhas, J. C., Beltrão, B. A., Souza Júnior, L. C., Morais, F., Mendes, V. A., Miranda, J. L. F. Recife: CPRM/PRODEEM, 2005.

Cotta, J. A. D. O., Carvalho, N. L. C., Brum, T. D. S., \& Rezende, M. O. D. O. (2015). Compostagem versus vermicompostagem: comparação das técnicas utilizando resíduos vegetais, esterco bovino e serragem. Engenharia Sanitária e Ambiental, 20, 65-78.

Danner, M. A., Citadin, I., Sasso, S. A. Z., Zarth, N. A., \& Mazaro, S. M. (2009). Fontes de cálcio aplicadas no solo e sua relação com a qualidade da uva'Vênus'. Revista Brasileira de Fruticultura, 31, 881-889.

Deperon, M. A., Nagahama, H. D. J., Olszevski, N., Cortez, J. W., \& Souza, E. B. (2016). Influência de implementos de preparo e de níveis de compactação sobre atributos físicos do solo e aspectos agronômicos da cultura do milho. Engenharia Agrícola, 36, 367-376.

Dias, D. S., \& Coelho, M. V. (2007). Efeito de íons Cu2+ e Zn2+ em atividade Ca-ATPásica isolada de larvas de Pachymerus nucleorum (Fabricius)(Coleoptera: Chrysomelidae, Bruchinae). Neotropical Entomology, 36, 65-69.

Domingues, L. D. S., Ribeiro, N. D., Andriolo, J. L., Possobom, M. T. D. F., \& Zemolin, A. E. M. (2016). Crescimento, produti vidade de grãos e acumulação de cálcio, potássio e magnésio em plantas de feijão relacionadas à nutrição com cálcio. Acta Scientiarum. Agronomy, 38, $207-217$.

Donagemma, G. K., Ruiz, H. A., Alvarez V, V. H., Ker, J. C., \& Fontes, M. P. F. (2008). Fósforo remanescente em argila e silte retirados de Latossolos após pré-tratamentos na análise textural. Revista Brasileira de Ciência do Solo, 32, 1785-1791.

EMBRAPA. (2006) Sistema brasileiro de classificação de solos. Rio de Janeiro: EMBRAPA-SPI.

EMBRAPA. (1997). Manual de métodos de análise de solo. Embrapa Solos-Documentos (INFOTECA-E) 
EMBRAPA. (2006). Marco Referencial em Agroecologia. Brasília, DF: Embrapa Informação Tecnológica.

Epstein, E., \& Bloom, A. P. (2006). Princípios e perspectivas. Londrina. editora planta.

Gliessman, S. R. (2001). Agroecologia: processos ecológicos em agricultura sustentável (p. 653). Porto Alegre: Ed. da UFRGS.

Inocencio, M. F., Carvalho, J. G. D., \& Furtini Neto, A. E. (2014). Potássio, sódio e crescimento inicial de espécies florestais sob substituição de potássio por sódio. Revista Árvore, 38, 113-123.

Ker, J. C., Curi, N., Schaefer, C. E. G. R., \& Vidal-Torrado, P. (Eds.). (2015). Pedologia: fundamentos. Sociedade Brasileira de Ciência do Solo.

Kuwahara, F. A., Souza, G. M., Guidorizi, K. A., Costa, C., \& Meirelles, P. R. D. L. (2016). Phosphorus as a mitigator of the effects of water stress on the growth and photosynthetic capacity of tropical C 4 grasses. Acta Scientiarum. Agronomy, 38, 363-370.

Leite, J. N. F., Cruz, M. C. P. D., Ferreira, M. E., Andrioli, I., \& Braos, L. B. (2016). Frações orgânicas e inorgânicas do fósforo no solo influenciadas por plantas de cobertura e adubação nitrogenada. Pesquisa Agropecuária Brasileira, 51, 1880-1889.

Lopes, A. S. (1998). Manual internacional de fertilidade do solo. Piracicaba: Potafos, 79-85.

Magalhães, A. G., Rolim, M. M., Duarte, A. D. S., Silva, G. F. D., Bezerra, E., \& Pedrosa, E. M. (2016). Macronutrient and sodium content in maize plants under cassava wastewater fertilization. Revista Brasileira de Engenharia Agrícola e Ambiental, 20, 215-222.

Matos, A. T. D., Vidigal, S. M., Sediyama, M. A. N., Garcia, N. C., \& Ribeiro, M. F. (1998). Compostagem de alguns resíduos orgânicos, utilizando-se águas residuárias da suinocultura como fonte de nitrogênio. Revista Brasileira de Engenharia Agrícola e Ambiental, 2, $199-203$.

Melo, R. M., Barros, M. D. F., Santos, P. M. D., \& Rolim, M. M. (2008). Correção de solos salino-sódicos pela aplicação de gesso mineral. Revista Brasileira de Engenharia Agrícola e Ambiental, 12, 376-380.

Nascimento, J. A., Souto, J. S., Pereira, W. E., Medeiros, S. A. D. S., \& Cavalcante, L. F. (2016). Macronutrients in watermelon plants fertilized with potassium and cattle manure. Revista Brasileira de Engenharia Agrícola e Ambiental, 20, 836-840.

Niero, L. A. C., Dechen, S. C. F., Coelho, R. M., \& Maria, I. C. D. (2010). Avaliações visuais como índice de qualidade do solo e sua validação por análises físicas e químicas em um Latossolo Vermelho distroférrico com usos e manejos distintos. Revista Brasileira de Ciência do Solo, 34, $1271-1282$.

Novais, R. F. (2007). Fertilidade do solo. Sociedada Brasileira de Ciência do Solo.

Oliveira, R. J., Gatiboni, L. C., Valicheski, R. R., Miquelluti, D. J., \& Brunetto, G. (2016). Calibração da adubação fosfatada e potássica para beterraba na região do Vale do Itajaí. Horticultura Brasileira, 34, 210-215.

Osaki, F. (1991). Calagem e adubação. Campinas: Instituto Brasileiro de Ensino Agrícola.

Partelli, F. L., Busato, J. G., Vieira, H. D., Viana, A. P., \& Canellas, L. P. (2009). Qualidade da matéria orgânica e distribuição do fósforo no solo de lavouras orgânicas de café Conilon. Ciência Rural, 39, 2065-2072..

Primavesi, A. (2002). Manejo ecológico do solo: a agricultura em regiões tropicais. NBL Editora.

Rodrighero, M. B., Barth, G., \& Caires, E. F. (2015). Aplicação superficial de calcário com diferentes teores de magnésio e granulometrias em sistema plantio direto. Revista Brasileira de Ciência do Solo, 39, 1723-1736.

Ribeiro, D. O., Castoldi, G., Rodrigues, C. R., da Silva, A. J., Pereira, R. M., \& Kuss, G. M. (2019). Atributos físicos e fertilidade de um latossolo submetido a aplicações sucessivas de cama de peru em pastejo rotacionado. In Colloquium Agrariae. ISSN: 1809-8215 (Vol. 15, No. 5, pp. 11-23).

Santos, D. de S. ., Barros, R. P. de ., Sousa, J. I. de ., Galdino, W. de O. ., Silva, M. G. dos S. ., Araújo, A. da S. ., Silva, D. dos S. ., Lima, F. da S. ., Neves, J. D. dos S. das ., \& Costa, J. G. da . (2021). Desenvolvimento inicial da fenologia da mamona (Ricinus communis L.) em diferentes substratos orgânicos. Research, Society and Development, 10(8), e14010817204.

Santos, R. D., Lemos, R. D., Santos, H. D., KER, J. C., Anjos, L. D., \& Shimizu, S. H. (2005). Manual de descrição e coleta de solo no campo.

Santos, J.E.B.; Nascimento, A.M.A; Santos, G.R.; Silva, A.B.; Araujo, K. D. (2017). Mesofauna do solo em remanescente de caatinga, santana do ipanema, Alagoas. Ciência Agrícola, v.15, p. 13-17.

Sales, R. P., Portugal, A. F., Moreira, J. A. A., Kondo, M. K., \& Pegoraro, R. F. (2016). Qualidade física de um Latossolo sob plantio direto e preparo convencional no semiárido. Revista Ciência Agronômica, 47, 429-438.

Silva, A. O. D., Silva, D. J., \& Bassoi, L. H. (2016). Nitrate and potassium concentration in fertigated soil cultivated with wine vines. Ciência $e$ Agrotecnologia, 40, 305-316..

Silva, G. F. D., Santos, D., Silva, A. P. D., \& Souza, J. M. D. (2015). Indicadores de qualidade do solo sob diferentes sistemas de uso na mesorregião do agreste paraibano. Revista Caatinga, 28, 25-35.

Silva, R. F., Negrini, A., Scheid, D. L., Basso, C. J., da Silva, J. C., \& Bertollo, G. M. (2019). Changes in edaphic mesofauna by successive application of pig slurry and poultry litter in Tifton 85 pasture. Revista Brasileira de Ciências Agrárias, 14(2), 1-8.

Silva, S. S., de Araújo Neto, S. E., Kusdra, J. F., \& Ferreira, R. L. F. (2007). Produção orgânica de mudas de couve-manteiga em substratos à base de coprolito de minhocas. Revista Caatinga, 20(4), 83-83. 
Research, Society and Development, v. 10, n. 10, e360101019014, 2021 (CC BY 4.0) | ISSN 2525-3409 | DOI: http://dx.doi.org/10.33448/rsd-v10i10.19014

Sociedade Brasileira de Ciência Do Solo. Comissão de Química e Fertilidade do Solo. (2004). Manual de adubação e de calagem para os Estados do Rio Grande do Sul e Santa Catarina.

Souza, A. P. S. B. (2010). Monitoramento do efeito residual da degradação e bioindicadores da recuperação do solo. 2010. Dissertação de Mestrado, Cruz das Almas-BA, Universidade do Recôncavo da Bahia - UFRB.

Souza, L. C. D., Lima, H. V. D., Rodrigues, S., Kern, D. C., Silva, Á. P. D., \& Piccinin, J. L. (2016). Chemical and physical properties of an anthropogenic dark earth soil from Bragança, Para, Eastern Amazon. Acta amazonica, 46, 337-344.

Vilar, C. C., \& Vilar, F. C. M. (2013). Comportamento do fósforo em solo e planta. Campo Digital, 8(2), 37 - 44.

Vilar, C. C., Costa, A. C. S. D., Hoepers, A., \& Souza Junior, I. G. D. (2010). Capacidade máxima de adsorção de fósforo relacionada a formas de ferro e alumínio em solos subtropicais. Revista Brasileira de Ciência do Solo, 34, 1059-1068.

Werle, R., Garcia, R. A., \& Rosolem, C. A. (2008). Lixiviação de potássio em função da textura e da disponibilidade do nutriente no solo. Revista Brasileira de Ciência do Solo, 32, 2297-2305.

Wohlenberg, E. V., Reichert, J. M., Reinert, D. J., \& Blume, E. (2004). Dinâmica da agregação de um solo franco-arenoso em cinco sistemas de culturas em rotação e em sucessão. Revista Brasileira de Ciência do Solo, 28, 891-900. 